\title{
Total unilateral pulmonary sequestration
}

\author{
MICHAEL B A TES \\ From North Middlesex Hospital, Edmonton, London, N.18
}

\begin{abstract}
A case is described of a baby boy aged 7 months who was found to have total sequestration of the right lung, the right main bronchus communicating with the lower end of the oesophagus. This was discovered during investigation for supposed asthma, as the child had wheezed since birth. No episodes of cyanosis or difficulties with feeding had occurred. The embryological considerations are discussed and reasons are given to account for this abnormality which must have occurred at the $5-\mathrm{mm}$. stage of development. This child is probably the first reported case of total pulmonary sequestration which has survived childbirth and subsequent pneumonectomy and now, when 6 years old, appears to have a reasonable life ahead.
\end{abstract}

\section{CASE HISTORY}

A baby boy aged 7 months was admitted to hospital on 20 October 1961 with a history of wheezing since the day of birth. He had never had any feeding difficulties or attacks of cyanosis. There was an unusual shape to the back of his head and webbing of the neck was present. The apex beat was found to be near the right nipple. The chest radiograph (Fig. 1) showed a marked mediastinal shift to the right. On bronchoscopy the instrument could only be passed just through the cords and then, due to acute angulation backwards of the trachea, could be passed no further. A bronchogram was carried out and this confirmed the posterior angulation of the trachea (Fig. 2) and also showed the total absence of a right bronchial tree and the presence of a normal left bronchial tree (Fig. 3). A penetrating chest radiograph was taken and, as a result of the air spaces seen in the right lung field, the child was given propyliodone (Dionosil) to swallow and this showed the presence of a large broncho-oesophageal fistula leading upwards from the oesophagus about $1 \mathrm{~cm}$. above the diaphragm (Fig. 4). As no other serious congenital abnormality could be found it was decided that this sequestrated lung should be removed before a severe infection developed. A right thoracotomy was performed on 7 November, when a free pleural space was found without evidence of effusion or infection. The lung was of normal size but was grey in colour, pneumonic

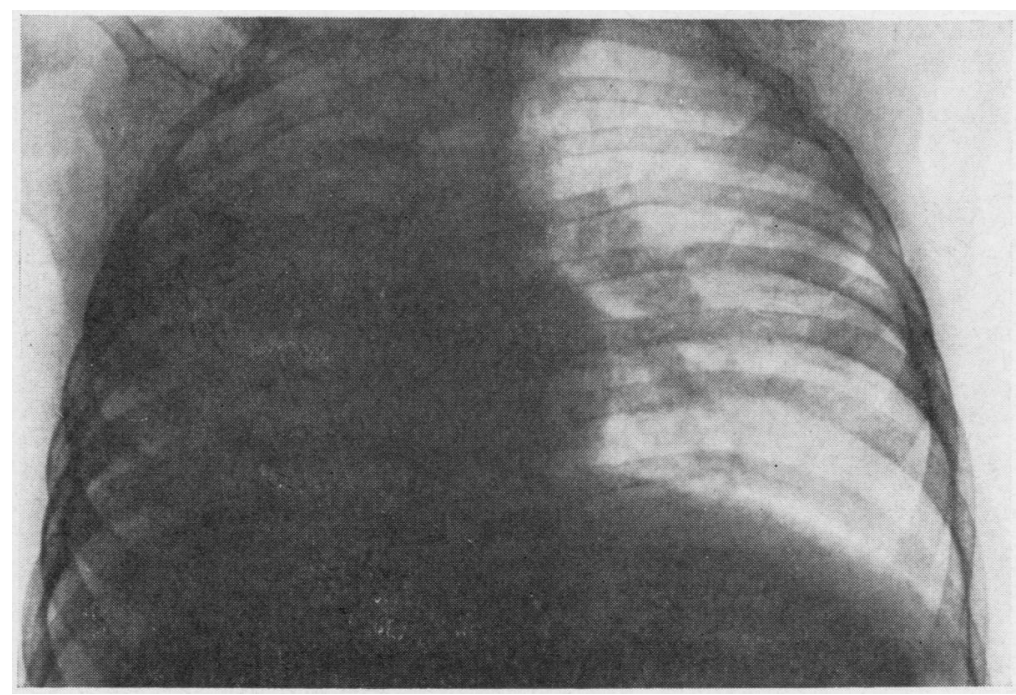

FIG. 1. Plain radiograph of chest showing collapse of right lung. 

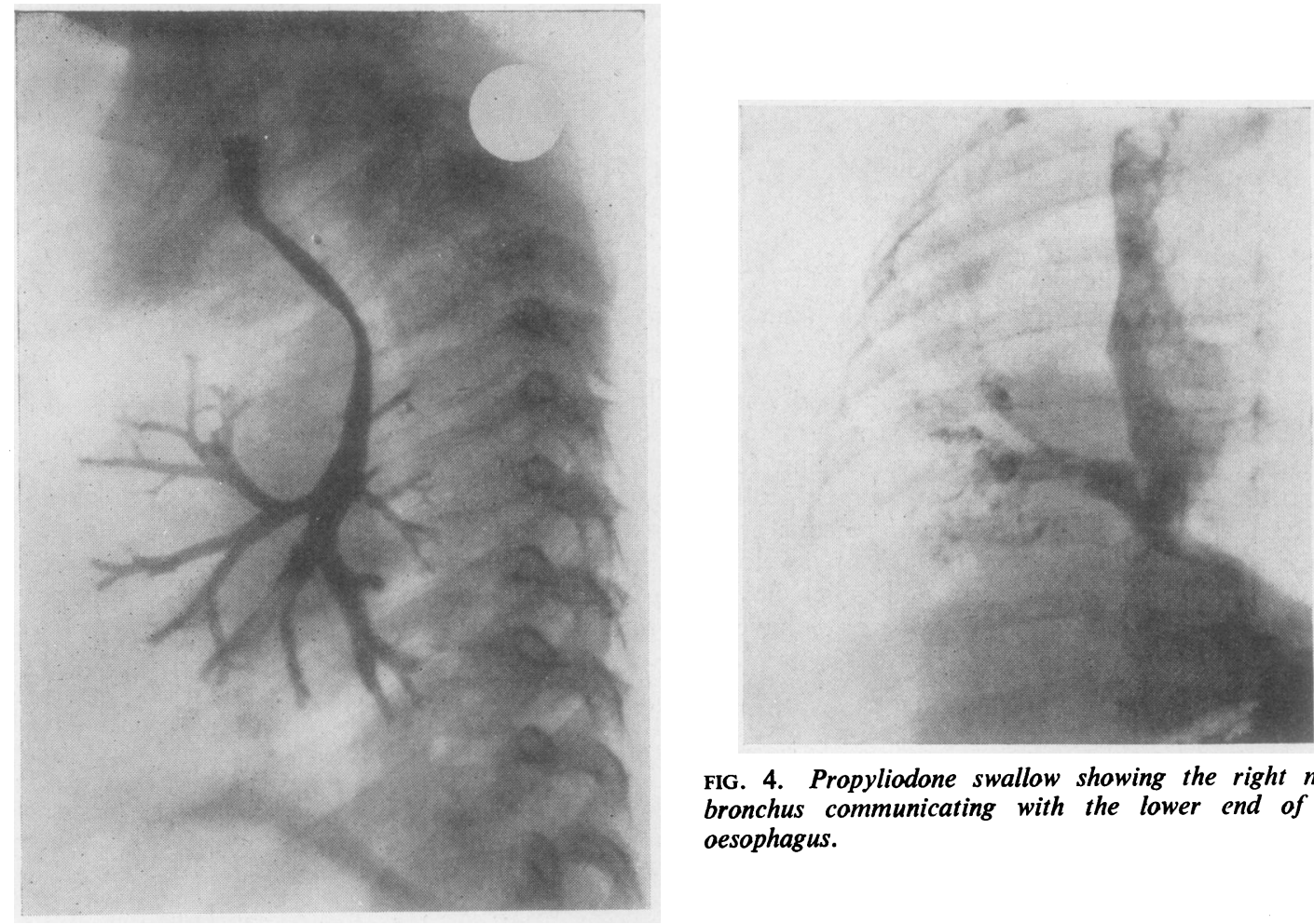

FIG. 4. Propyliodone swallow showing the right main bronchus communicating with the lower end of the oesophagus.

FIG. 2. Lateral bronchogram showing posterior angulation of the trachea just distal to the larynx.

FIG. 3. P.A. bronchogram showing a normal left lung and complete absence of a right bronchial tree. 


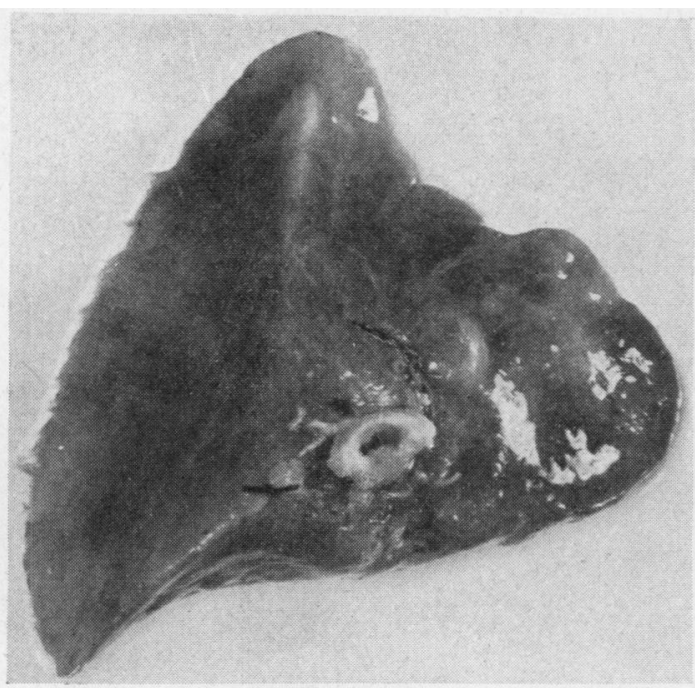

FIG. 5. External appearance of right lung showing cut end of the bronchus and absence of fissures.

in consistency, and had no fissures (Fig. 5). There was a thick-walled bronchus, $1.5 \mathrm{~cm}$. in diameter, connecting the lung to the oesophagus and situated $1 \mathrm{~cm}$. above the diaphragm. This was divided, and the oesophageal opening was closed with interrupted silk sutures. Immediately above the bronchus was a small, thick-walled artery, $2 \mathrm{~mm}$. in diameter, which originated behind the pericardium and had the appearance of a bronchial artery (although subsequent histological section showed it to have the pattern of a pulmonary artery as described by Abbey Smith (1955) ). An adjacent vein, $3 \mathrm{~mm}$. in diameter, appeared to drain into the left atrium. Both these vessels were ligated and divided and the lung was removed. The chest was closed without drainage and the postoperative course was uneventful.

EXAMINATION OF THE SPECIMEN On the cut surface the lung tissue was airless and the bronchi and bronchioles were markedly thickened and slightly dilated (Fig. 6). Histological section of the lung showed chronically inflamed and dilated bronchi and bronchioles containing little or no exudate with some emphysematous changes. Some of the alveoli contained macrophages and red blood cells. A section from the cut end of the bronchus showed bronchial glands and cartilage in the wall. The epithelium was mainly thin and columnar, but at one point it was squamous and stratified.

Opaque material was then injected up the bronchus (Fig. 7), and this demonstrated the multiple radiating bronchi arising from a single stem, thus fixing the stage of development at which this abnormality must have occurred at $5 \mathrm{~mm}$.; by this stage the primitive lung bud has divided only into right and left primary stem bronchi with no further developments of two lateral bronchial buds, or of fissures, which occur on the right side at the $7 \mathrm{~mm}$. stage.

Opaque material was also injected into the artery and this shows a very poor vascular supply to the lung, having more the appearance and distribution of a bronchial artery than a pulmonary artery.

Pryce (1946) reported seven cases of intralobar sequestration with abnormal arterial supply from the aorta, and enlarged on Rektoržik's theory (1861) of sequestration, whereby the whole or part of the primitive lung bud becomes captured by the abnormal systemic artery.

\section{EMBRYOLOGICAL CONSIDERATIONS}

In their classic article on intralobar sequestration of the lung, Pryce, Sellors, and Blair (1947) discuss in great detail the two different theories of origin of extralobar sequestration or lower accessory lung. They favoured the theory of sequestration. The accessory theory of Eppinger (1904) regards the lung mass as arising from an extra lung bud. In this article Pryce et al. (1947) showed a series of diagrams illustrating the various types of sequestration described by different authors, and Fig. 5 shows a case described by Klebs (1874,

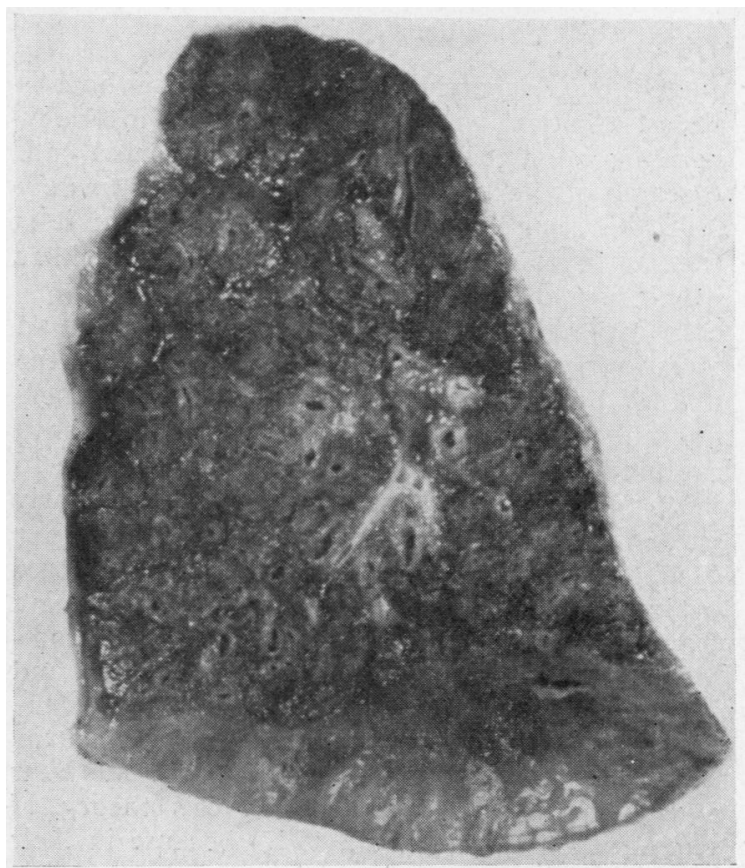

FIG. 6. Cut surface of the right lung showing thickening of the bronchial walls. 


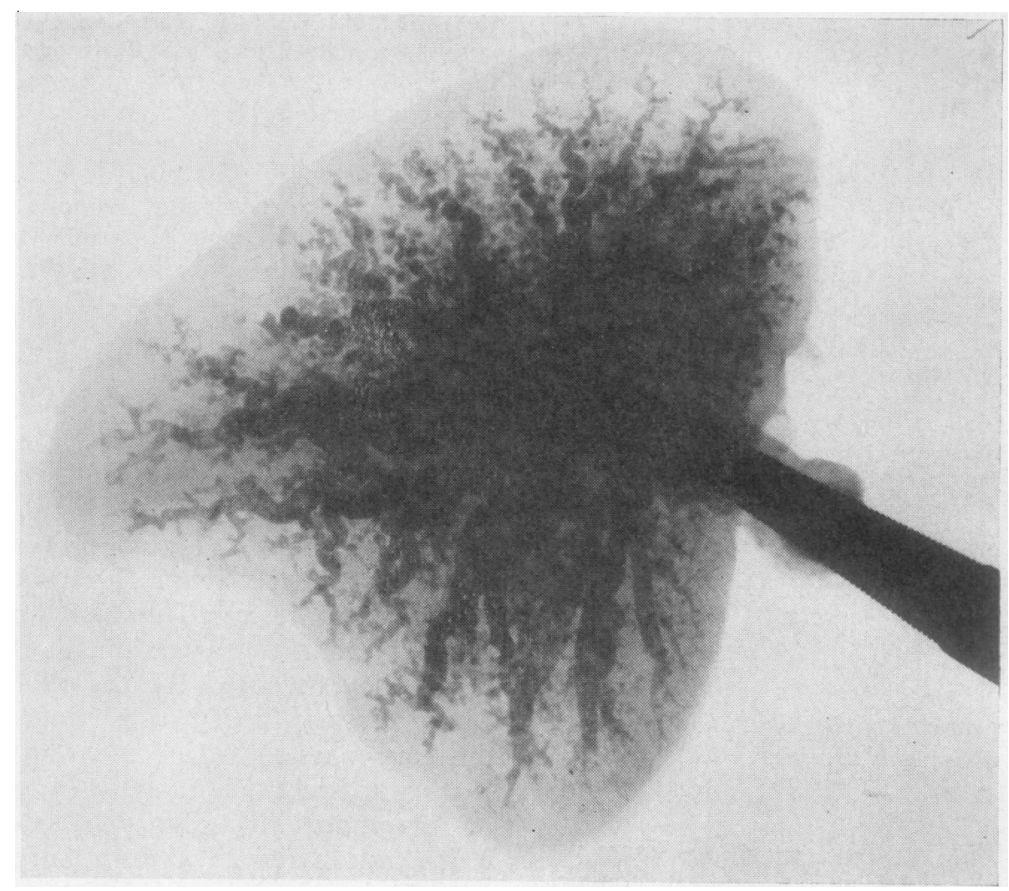

FIG. 7. Propyliodone injection into right main bronchus showing multiple bronchi radiating from a single stem.

quoted by Gruenfeld and Gray, 1941) which is almost identical with mine, except that in Klebs' case the bronchus had a blind oesophageal end. A search of the medical libraries has unfortunately failed to secure Klebs' original article, but it is reasonable to assume that the child was either stillborn or died soon afterwards.

In my patient it is difficult to imagine how an artery which was only $2 \mathrm{~mm}$. in diameter at the time of operation, and must have been extremely fine and delicate at the $5 \mathrm{~mm}$. stage, could have captured the first right bulbous tip, giving rise to this total unilateral sequestration, particularly when the bronchus communicated with the lower oesophagus. Scheidegger (1936) described a case of lower accessory lung with a pedicle running from the cardia of the stomach, but not communicating with it, through the diaphragm and joining with a bronchial tube just above the diaphragm. This tube appeared to be like the oesophagus and contained no cartilage. Baar and d'Abreu (1949) doubted Pryce's theory of sequestration (Pryce et al., 1947) because in their two reported cases the accessory lungs were supplied by a branch of the pulmonary artery and not by an abnormal vessel arising from the aorta.
Flint (1906) emphasized that the arteries are only passive followers of the bronchi in development and arise secondarily from the capillary mesh which envelops them. This view is held by Jones (1955) in an article reporting 19 cases of develop- $\frac{x}{0}$ mental bronchopulmonary defects in which he 3 . considered that the aberrant systemic artery was secondary and compensatory rather than the prime determining factor in congenital lung defects. At $\mathrm{O}$ the $3.5 \mathrm{~mm}$. stage the oesophagus is only $0.5 \mathrm{~mm}$. in length and the pharynx virtually joins on to the stomach. The abnormality must start at this early stage when the lowest part of the oesophageal os tracheal groove remains patent. Partial epithelial N occlusion of the oesophagus also takes place at N this time, but this is normally a transient feature. It is suggested in this case that the rapid oesophageal elongation, which now follows, resulted in $\stackrel{0}{\circ}$ the fistula occurring at the level of the diaphragm due to a persistence of a communication via the oesophago-tracheal groove. At this stage the ${ }_{0}^{\circ}$ oesophagus is lined by ciliated columnar epithe- $\overrightarrow{\mathbb{D}}$ lium and therefore might have a pulmonary $\frac{}{\mathbb{D}}$ potential sufficient to form a lung bud at the site $\stackrel{\varrho}{O}$ of this communication in the oesophago-tracheal groove. 
Halasz, Lindskog, and Liebow (1962) described a case of right lower lobe sequestration with a fistula between the oesophagus and the medial basal bronchus, and they considered that this resulted not from the normal lung bud but from a more caudal diverticulum of the foregut. Davidson (1956) described an accessory left lower lobe with oesophageal communication, and he considered it to be more likely that the accessory lung tissue and communicating oesophageal tube had arisen as an independent bud from the foregut rather than having been sequestrated from the primitive lung bud by the abnormal artery from the abdominal aorta.

It is clear from the reported cases and theories postulated that it is difficult, if not embryologically impossible, to make every sequestration fit into one of the two main theories, and therefore some may result from sequestration by a systemic artery and some from an accessory lung bud arising from the foregut at diaphragmatic level.

\section{DISCUSSION}

It is interesting to note that no infection had occurred in this sequestrated lung in spite of its poor blood supply and its free communication with the oesophagus. On screening, it was seen that barium, and therefore food, flowed freely into the right lung whenever the child swallowed. As the bronchus was directed slightly headwards, as can be seen in Fig. 4, free and dependent drainage must have prevented the development of bronchopneumonia. In intralobar sequestration repeated infections are liable to occur due to inadequate bronchial drainage.

In 1966 the child developed a torticollis and radiographs of the cervical spine demonstrated a congenital hemivertebra, an abnormality also noted by Jones (1955) in two of his cases.

I should like to thank Dr. Ian Wickes for permission to publish details of this case.

\section{REFERENCES}

Baar, H. S., and d'Abreu, A. L. (1949). Duplications of the foregut. Brit. J. Surg., 37, 220.

Davidson, J. S. (1956). A case of congenital oesophageal diverticulum, lower accessory lobe, and oesophagobronchial fistula. Ibid., $\mathbf{4 3}$ 417.

Eppinger, H. (1904). Krankheiten der Lungen. A. Angeborene Krankheiten. Ergebn. allg. Path. path Anat., 1902, 8, Pt 1, p. 267

Flint, J. M. (1906). The development of the lungs. Amer. J. Anat., 6, 1. Gruenfeld, G. E., and Gray, S. H. (1941). Malformations of the lung. Arch. Path., 31, 392.

Halasz. N. A., Lindskog, G. E., and Liebow, A. E. (1962). Esophagobronchial fistula and bronchopulmonary sequestration. Ann. Surg., 155, 215.

Jones, P. (1955). Developmental defects in the lungs. Thorax, 10, 205. Klebs, E. (1874). Missbildungen der Lunge. Aerztl. Cor-bl. f. Böhmen, $2,111$.

Pryce, D. M. (1946). Lower accessory pulmonary : rtery with intralobar sequestration of lung: a report of seven cases. J. Path. Bact., 58, 457.

- Sellors, T. H., and Blair, L. G. (1947). Intralobar sequestration of lung associated with an abnormal pulmonary artery. Brit. J. Surg., 35, 18.

Rektoržik, E. (1861). Ueber accessorischen Lungenlappen. Wochenblatt der Zeitsch. ges. Aerzte in Wien, 17, 4.

Scheidegger, S. (1936). Lungenmissbildungen. Frankfurt Z. Path., 49, 362.

Smith, R. Abbey (1955). Intralobar sequestration of the lung. Thorax, $10,142$. 